\title{
Fiscal Consolidation: An Exercise in the Methodology of Coordination
}

\author{
Guglielmo Maria Caporale \\ Michael Chui \\ European Central Bank \\ Stephen G. Hall \\ Imperial College Management School \\ Brian Henry \\ Oxford University
}

London South Bank University and London Metropolitan University

\begin{abstract}
This paper outlines a new methodology for the study of international policy coordination, which builds on two separate approaches previously used in the literature: optimal simple rules, and game-theoretic analysis. The new approach is illustrated by using the example of a changed target for the debt-income ratio in the $G-3$. The results suggest that there are few policy externalities when only fiscal policy is coordinated, whilst coordination of both fiscal and monetary policy results in substantial externalities and welfare improvements. Our findings reflect the fact that, unlike earlier studies, we focus on the strategic interaction between (domestic) policy makers, as well as the standard exchange rate and interest rate transmission mechanisms.
\end{abstract}

- JEL Classification: C5, E1, F4

\footnotetext{
*Corresponding address: Professor Guglielmo Maria Caporale, Brunel Business School, Brunel University, Uxbridge, Middlesex UB8 3PH, UK. Tel: +44 (0)895 2003327. Fax: +44(0)1895 269770. Email: Guglielmo-Maria.Caporale@brunel.ac.uk

(C2005-Center for International Economics, Sejong Institution, All Rights Reserved.
} 
- Key words: Optimal Control, Inflation Targets, Fiscal Consolidation, International Policy Coordination

\section{Introduction}

This paper is concerned with fiscal consolidation or "restructuring" in the developed countries (a central concern in recent years as evidenced by the fiscal cuts in the US (the Omnibus Reconciliation Act (1993)), and in Europe to achieve the Maastricht conditions), and more generally with the analysis of policy coordination when the instigating policy change is fiscal, more specifically a reduction in the debt to income ratio over time. Of course, such moves by individual countries produce spillovers, or external effects on other countries, which rational governments try to exploit for the benefit of their own citizens, therefore obtaining overall fiscal positions which are different from those based on domestic objectives in the absence of the externality (see Persson and Tabellini (1995)).

We introduce a more general methodology which brings together two strands of the literature on policy coordination, one based on simple feedback rules for policy design, the other on optimising and the game theoretic approach. In both strands uncertainty, including model uncertainty, has been a problem highlighted in some previous work. (see, in particular, Holtham and Hughes-Hallett (1987) and Bryant (1995)). One response to the issue of uncertainty has been the use of stochastic simulations to calculate explicit model prediction standard errors, in order to place confidence intervals around previous deterministic solutions (see, e.g., Taylor's (1993)). Another takes a range of models, so the robustness of predictions to model specification can be checked. Ours is a further extension to these approaches. Furthermore, an estimated model of the G-3 is used with a coherent theoretical structure, and long-term empirical properties based on cointegration methods. Finally, unlike previous studies, we use simple rules of the proportional, integral and derivative (p.i.d.) form for fiscal and monetary policy, and determine the weights on these rules using optimal control methods. Spillovers are then evaluated in a range of multi-country exercises, ranging from single country to fully cooperative. ${ }^{1}$

\footnotetext{
${ }^{1}$ For a brief but comprehensive survey of previous empirical studies on policy coordination, see Caporale
} (1996). 
Extant analyses of the international consequences of fiscal consolidations are marked by the diversity of methods, models, and stochastic assumptions used. While there is broad agreement that deficit reductions may have an effect on output, there is considerable debate about the timing of these effects. Deficit reductions produce decreases in aggregate demand initially, and may, or may not, also lead to falls in long-term interest rates which should stimulate growth later. It is the latter part of this sequence, i.e., the links between fiscal policy and asset prices (interest rates), and thence between asset prices and expenditures, which is the object of controversy. In a world where Ricardian equivalence holds, under the $\mathrm{REH}$, consumers internalise the change in the deficit, their saving does not alter, hence nor does the interest rate. (See McKibbin (1993)). Evidence on possible links between fiscal stance and asset prices is, however, mixed. Barro (1989), for instance, does not find a link between interest rates and budget deficits, whilst Tanzi and Lutz (1991) report that there is a positive correlation. The specific fiscal instrument considered also matters. McKibbin, op cit., for example, finds radically different effects when using corporate tax as compared with income tax or government spending cuts, and so do Bartolini et al. (1995), who investigate the effects of four fiscal instruments - a labour income based tax, a capital income tax, a consumption tax and government expenditure.

Turning to the international effects, there have been many studies which have estimated the likely macroeconomic effects of fiscal consolidation and some provide an analysis of the multilateral consequences of such moves (a recent one is Douven and Peeters (1997)). In some, the methods used are in the nature of simulation exercises: the proposed fiscal changes are applied in a multi country econometric model usually by "exogenous" changes in tax rates or government expenditures, and the resulting effects both in the originating country and overseas are given by the dynamic responses of the model to the exogenous shock. The basis for this sort of exercise is most clear when they are in the nature of ex-post simulations. These aim to establish what the effects of known changes in fiscal policy on output and inflation etc were over a past period. (see, for example, McKibbin (1993) and Bartolini et al. (1995)). According to such exercises the likely effects of the consolidation will vary over time, both nationally and internationally.

The international effects of a fiscal consolidation undertaken in a particular country generally are thought to depend on three factors: the changes in the originating country's output (which through chages in net trade affects other countries), its 
interest rate effects (given the changes in the risk premium), and any effect on the real exchange rate produced by interest rate changes. Beggar-thy-neighbour effects of fiscal consolidation are found in some empirical models using the simulation approach described above. These findings contradict the "standard" MundellFleming implication that fiscal policy tends to be "locomotive" with positive spillovers and monetary policy beggar-thy-neighbour, with negative spillovers. Douvan and Peeters (op.cit), for example, report that simulations on MG2 and Multimod generally confirm the finding that, although positive initially, fiscal policy spillovers become increasingly negative subsequently. (See p.29). It should be noted that the estimated size of these spillovers differs markedly between different models, and according to the monetary policy regime assumed. Helliwell and Padmore (1985), Frankel (1988) and Whitley (1992) have, in different ways, considered the effects of a US ficsal expansion under alternative monetary and exchange rate regimes. Shocks to GDP appear to have much smaller effects under floating exchange rate regimes than when the exchange rate is fixed (see Douven and Peeters (1997), and Taylor (1993)). One of the principal transmission mechanisms (stronger than trade effects) is through the real interest rate (see Douven and Peeters (1997)).

Standing apart from simulation studies is the literature on coordination which uses policy optimisation in one form or another. Broadly speaking the analytical issue posed is that of the potential gains in moving from a Nash non-cooperative to a Nash cooperative bargaining solution (see Bryant (1995). The theoretical insight from static models has been that Pareto efficient solutions are possible with countries agreeing to coordinate their policies to minimise a joint loss function, which dominate Nash non-cooperative equilibria. With rational expectations and dynamics, repeated games and the questions of reputational equilibrium arise. Rogoff (1985) showed that cooperation without reputation could be counterproductive. Other work has shown that reputation with cooperation may also be counterproductive (see Currie and Levine (1993)).

Many studies have used small calibrated models to evaluate gains from policy coordination (e.g. the original paper by Oudiz and Sachs (1985)), while others have used an empirical model (Hughes-Hallett (1989)), or a range of empirical models (Holtham and Hughes-Hallet (1992)) for example). Beginning with the study by Oudiz and Sachs (1985) the conventional wisdom from studies in this mode has been that incremental gains to coordination are small. Bryant (1995), however, emphasises the uncertainty surrounding this conclusion: different models give 
different estimates, and the results depend on the formulation of cooperative and non-cooperative solutions used. More recent studies have questioned the conventional view by arguing, e.g., that the gains from cooperation depend not only on individual government's reputation but also on the size of shocks (see Currie et al, 1997), or by pointing out that the findings differ (and should be expected to differ) between small and large countries, and that larger gains are likely to follow from coordination among the large countries, especially the largest - the G3 (see Bryant, op. cit).

The present paper takes a different approach to the analysis of fiscal consolidation, and provides a normative analysis of fiscal shocks by optimising endogenous policy rules using an empirical model of the G3. By using an explicit "simple" policy rule it overcomes some of the disadvantages of earlier studies which simulate the effects of an exogenous policy change without an explicit policy framework including explicit policy objectives, and unlike Taylor's method (1989, 1993 ) it derives this rule in an optimal way. The plan of the paper is as follows. Section 2 discusses the empirical model of the G3 used for the policy simulation exercises. Section 3 briefly describes some of the alternative optimisation methods used in the literature, including the present one. The policy optimisation exercises are reported in Section 4. Section 5 concludes.

\section{A Model of the G3 Economies}

This section describes the model of the G-3 which we use to conduct the policy simulations; further details (including diagnostics) can be found in Caporale et al $(1997 a, b)$. The theoretical setup combines a supply side which is based consistently upon assumptions about technology (a Cobb-Douglas production function is used for simplicity, but the model may be readily extended to other technologies, and a simplified, but realistic demand side. The factor demand equations and price equations are specified in a theoretically consistent way with the production function embodying all the cross equation restrictions implied by the theory (unlike the IMF's MULTIMOD or the McKibbin-Sachs model, for example). Our setup has ingredients both from New Keynesian theories and the neo-classical synthesis. Imperfect competition is assumed at the microeconomic level and wages are set by a union-firm bargain. The structure, as it is based on imperfect competition, does not determine aggregate output from the production function, but aggregate supply decisions instead determine aggregate prices relative to wages (usually referred to 
as the "markup" of prices on wages - see Layard, Nickell and Jackman (1991)).

To be more specific, the model comprises three country blocks, which are essentially similar in structure, although they differ by virtue of their estimated parameters of course. A distinguishing feature of the model is essentially to blend econometric estimation with a consistent and rigorous treatment of the supply side of the economy. The demand side is broadly conventional, consisting of a set of reasonably standard aggregate demand components, which sum to produce total demand. The supply side then is based around a production function and the corresponding derivation of factor demand equations and wage and price equations. The model equations embody the full set of cross equation restrictions implied by a profit maximising firm working within a constraint on total output coming from the demand side of the economy.

The methods used to estimate the model exploit systems approaches to estimating Vector Error Correction Models (VECMs). An important characteristic that we exploit is that of the reduced rank characteristic of such systems. In brief, for a set of non-stationary variables let $m$ cointegrating vectors (CVs) exist, then we may write the model as,

$$
\Delta Y_{t}=\theta(L) \Delta Y_{t-1}+\alpha \beta^{\prime} X_{t-1}+\varepsilon_{t}
$$

where $\beta^{\prime} X_{t}$ is the set of $C V s$, where $X=(Y, Z)$, and the variables are partitioned into endogenous (Y) and weakly exogenous variables $(\mathrm{Z})$. The $\mathrm{CVs}$ do not enter the dynamic equations for the weakly exogenous variables. Equation (1) above is then the conditional model. There is an accompanying marginal model (which we do not state here). The adjustment matrix $\alpha$ is of dimension $\mathrm{n} \mathrm{x} \mathrm{m}$, but it is not typically diagonal: each dynamic equation may include more than one CV.

An important feature of the model is that short and long run and indeed aggregate supply and demand are linked through investment decisions. Capital is treated as fixed in the short run, when firms and unions make their price and wage decisions. The capital stock adjusts according to a separate equation for investment (although this is dependent on the same technology assumptions as made elsewhere in the model). A transmission mechanism of changes in monetary and fiscal policy is that they affect investment and, by the familiar accumulation equation, the capital stock and the model's supply side. Cross-equation restrictions are imposed to ensure that the capital stock does not determine the model's equilibrium level of unemployment. 
The demand side follows the neo-classical synthesis. Investment is modelled as a function of the assumed technology, expected demand and the cost of finance. Consumption depends upon disposable income, interest rates and wealth, and net trade upon relative (to trading partner countrys) income and competitiveness. The trade sector implements a symmetric structure, with two bilateral export equations for each country, imports for each country being given by the other countries exports. The single asset price is the nominal exchange rate (actually, two bilateral rates between the dollar and the Yen, and the dollar and the DM), which is modelled as a "jump" variable (see Dornbusch (1976)). ${ }^{1}$ Hence the model exhibits overshooting in the real exchange rate (or in competitiveness) due to the combination of backward looking elements in the aggregate price setting (e.g. due to the adjustment costs of changing prices) and the forward looking behaviour of the exchange rate. Having outlined some of the main features of the model, we now provide a more detailed description of its specification.

\section{Aggregate supply}

The model of supply hypothesises that the representative firm is imperfectly competitive, and is constrained by a technology which involves variable, and both fixed and quasi-fixed factors. Wage, price and employment equations may be derived, in standard fashion, assuming the firm maximises the present value of discounted profits, subject to technological constraints. An alternative is to base the model on an intertemporal Nash bargain. Amongst other things, the present approach draws a sharp distinction between the short-run and long-run NAIRU, depending on the economic accounting period assumed. Thus for the short run, assuming the capital stock is fixed, pricing and employment decisions are based on familiar optimising subject to the restricted conditional (variable) cost function, $E$,

$$
E=E(W, P, P ; Y, K, t) \text {; }
$$

in general. Hence $P_{i}\left(P_{j}\right)$ is the factor price of the $i$ th (jth) input, $Y$ is output and $K$ the (given) capital stock. The time trend is included to represent exogenous neutral technical progress. Assuming that the variable cost function is twice differentiable, a constant product demand elasticity, and profit maximising, then price will be set as a constant markup over marginal cost

$$
P=\varepsilon \cdot \frac{\partial E(.)}{\partial Y},
$$

where $\varepsilon$ is the markup. In turn, employment, $L$, is determined from $E($ ) above 
by Shepherd's lemma,

$$
L=\frac{\partial E(.)}{\partial W}
$$

The wage is the outcome of an asymmetric Nash bargain between the employees (the "union") and the firm, which - assuming a Stone-Geary functional form depends on optimising the asymmetric objective function $\left(P_{i}\right)$

$$
\Pi=\left(W / W^{*}\right)^{\theta}\left(L / L^{*}\right)^{1-\theta}
$$

where $W^{*}$ and $L^{*}$ are the fall back levels of the real wage and employment respectively. In general the real wage equation which results depends upon the (determinants of the) fall back real wage and the discrepancy between employment and fall back employment $\left(L^{*}\right)$. In the model which follows, we assume that the principal determinant of the fall back wage $W^{*}$ is the level of unemployment $(U)$, and that $L^{*}$ depends only upon actual employment $(L)$ (see Layard, Nickell and Jackman (1991)).

\section{Production}

Assuming the production function is a Cobb-Douglas, then

$$
Y_{t}=A K_{t}^{\alpha} K_{t}^{1-\alpha}: A=A_{0} \exp ^{\beta t}
$$

where $Y$ is total product, $K$ is capital stock, $L$ is labour demand and $A$ is a measure of technology change. In logs this is

$$
y_{t}=a_{0}+\beta t+\alpha k_{t}+(1-\alpha) l_{t}
$$

in obvious notation.

Factor demands (employment in the present case) and pricing depend upon the representation of the cost function. Specifically, in the short run, this conditional cost function will depend upon the levels of variable costs, given the fixed factors. By Shepherd's Lemma, the ith conditional factor demand is then $\partial e / \partial w_{i}$ where $\mathrm{e}$ is the conditional cost function and $w_{i}$ the ith factor price. Thus for employment, 


$$
L_{t}=\left(Y_{t} A_{0}^{-1} \exp ^{-\beta t} K_{t}^{-\alpha}\right)^{1 /(1-\alpha)},
$$

or in log form (small letters are used to represent the variables in logs),

$l_{t}=$ constant $+\frac{1}{1-\alpha} y_{t}-\frac{\beta}{1-\alpha} t-\frac{\alpha}{1-\alpha} k_{t}$.

Also, assuming constant product demand elasticity, output price is given by

$$
p=\varepsilon \cdot \frac{\partial e}{\partial y},
$$

where $\varepsilon$ is the markup, and $\partial e / \partial y$ is marginal cost. In the C-D case, where the price for total output (the GDP deflator) is $\mathrm{P}$, and the factor price for labour is W, then from (9),

$$
P_{t}=\text { constant }+w_{t}-(1-\alpha)-\frac{\beta}{1-\alpha} t-\frac{\alpha}{1-\alpha}(y-k)_{t}
$$

The wage equation is then

$$
w_{t}=\text { constant }+p_{t}+(1-\alpha)-\frac{\beta}{1-\alpha} t-\frac{\alpha}{1-\alpha}(y-k)_{t}+\delta_{1} u_{1}
$$

where $\mathrm{U}$ is unemployment.

Lastly, by using a simple relation between employment and the working population, we have

$$
U_{t}=\frac{L_{t}^{w}-L_{t}}{L_{t}}
$$

where $L_{t}^{w}$ is the total working population.

This completes the static form of the supply side. Dynamics are incorporated in standard fashion using Error Correction Models (ECMs). Thus for the wage, price and employment equations, we extend the model to the open economy distinguishing between domestic and import prices. To do this, instead of the wage variable, $w_{t}$, in the price equation, we use a weighted average of the import price, $p_{t}^{m}$ and the wage, $w_{t}$. The equations then embody distinct cross-equation restrictions. Thus, in simple error-correction forms:

$$
\Delta p_{t}=\gamma_{1} \Delta p_{t}+\psi_{1}\left[-p_{t-1}-m_{1}-\beta^{*} t+\left(\kappa_{1} p^{m}+\kappa_{2} w\right)_{t-1}+\alpha^{*}(y-k)_{t-1}\right]
$$




$$
\begin{gathered}
\Delta w_{t}=\gamma_{2} \Delta w_{t}+\psi_{2}\left[-w_{t-1}+m_{2}+\beta^{*} t+p_{t-1}-\alpha^{*}(y-k)_{t-1}+\delta u_{t-1}\right] \\
\Delta l_{t}=\gamma_{3} \Delta l_{t-1}+\psi_{3}\left[l_{t-1}+m_{3}+\left(\alpha^{*}+\alpha\right) y_{t-1}-\beta^{*} t-\alpha^{*} k_{t-1}\right]
\end{gathered}
$$

where $\kappa_{1}+\kappa_{2}=1$, m's are arbitrary constants, $\beta^{*}=\beta /(1-\alpha)$. and $\alpha^{*}=\alpha /(1-\alpha)$.

\section{Some important equations in the model}

We list here the estimated wage, price, employment and the bilateral export equations for the model. In what follows, the production function is calibrated as follows:

\begin{tabular}{cccc}
\hline & US & Germany & Japan \\
\hline Capita Share $(\alpha)$ & 0.36 & 0.370 & 0.4500 \\
Time trend $(\beta)$ & 0.00 & 0.006 & 0.0025 \\
\hline
\end{tabular}

Wage Equation

US:

$$
\Delta w_{t}=0.08-0.29 \Delta w_{t-1}-0.09 \mathrm{ECMW}_{t-1}+0.6 \Delta p_{t}
$$

$$
\mathrm{ECMW}_{t}: w_{t}-p_{t}-\frac{\beta t}{1-\alpha}+\frac{\alpha}{1-\alpha}(y-k)_{t}+0.015 u_{t}+8.29
$$

$$
\Delta w_{t}=0.011-0.163 \Delta w_{t-1}-0.117 \mathrm{ECMW}_{t-1}-0.095 \Delta p_{t},
$$

Germany: $\operatorname{ECMW}_{t}: w_{t}-p_{t}-\frac{\beta t}{1-\alpha}+\frac{\alpha}{1-\alpha}(y-k)_{t}+0.0052 u_{t}+10.61$ :

$$
\Delta w_{t}=0.028+0.89 \Delta w_{t-4}-0.20 \mathrm{ECMW}_{t-1}+0.75 \Delta p_{t-1} \text {, }
$$

Japan:

$$
\mathrm{ECMW}_{t}: w_{t}-p_{t}-\frac{\beta t}{1-\alpha}+\frac{\alpha}{1-\alpha}(y-k)_{t}+0.02 u_{t}+7.28
$$

Price Equation

US:

$$
\Delta p_{t}=0.00+0.58 \Delta p_{t-1}-0.29 \Delta p_{t-3}-0.05 \mathrm{ECMP}_{t-1},
$$

$$
\begin{aligned}
& \mathrm{ECMP}_{t}: p_{t}-0.97 w_{t}+\frac{\beta t}{1-\alpha}-\frac{\alpha}{1-\alpha}(y-k)_{t}-0.03 p_{t}^{m}-8.24 \\
& \Delta p_{t}=0.0011+0.54 \Delta p_{t-1}+0.024 \Delta p_{t-4}-0.24 \mathrm{ECMP}_{t-1},
\end{aligned}
$$

Germany:

$$
\mathrm{ECMP}_{t}: p_{t}+-0.9 w_{t}=\frac{\beta t}{1-\alpha}-\frac{\alpha}{1-\alpha}(y-k)_{t}-0.1 p_{t}^{m}-9.75
$$

$$
\Delta p_{t}=0.0040+0.098 \Delta p_{t-1}+0.32 \Delta p_{t-3}-0.11 \mathrm{ECMP}_{t-1} \text {, }
$$

Japan:

$$
\mathrm{ECMP}_{t}: p_{t}-0.84 w_{t}+\frac{\beta t}{1-\alpha}-\frac{\alpha}{1-\alpha}(y-k)_{t}-0.16 p_{t}^{m}+6.65 \text {. }
$$


Employment equation

US:

$$
\Delta l_{t}=0.0060+1.23 \Delta l_{t-1}-0.43 \Delta l_{t-2}-0.013 \mathrm{ECML}_{t-1},
$$

$$
\mathrm{ECMP}_{t}: l_{t}-\frac{1}{1-\alpha} y_{t}+\frac{\beta t}{1-\alpha}+\frac{\alpha}{1-\alpha} k_{t}-2.089
$$

$$
\Delta l_{t}=0.0036+0.09 \Delta l_{t-2}+0.5 \Delta y_{t}-0.033 \mathrm{ECML}_{t-1} \text {, }
$$

Germany:

$$
\mathrm{ECMP}_{t}: l_{t}-\frac{1}{1-\alpha} y_{t}+\frac{\beta t}{1-\alpha}+\frac{\alpha}{1-\alpha} k_{t}-5.232
$$

$$
\Delta l_{t}=0.0032+0.8 \Delta l_{t-2}-0.013 \mathrm{ECML}_{t-1} \text {, }
$$

Japan:

$$
\mathrm{ECMP}_{t}: l_{t}-\frac{1}{1-\alpha} y_{t}+\frac{\beta t}{1-\alpha}+\frac{\alpha}{1-\alpha} k_{t}-2.09 .
$$

Bilateral Export Equation

$$
\begin{aligned}
& \Delta x_{U S, G E, t}=-1.75-0.033 \Delta x_{U S, G E, t-1}-0.54\left[\left(x_{U S, G E}-y_{U S}\right)_{t-1}\right. \\
& \left.-0.6\left(y_{G E}-y_{U S}\right)+0.42 r p_{U S, G E, t-1}+0.67 \phi_{G E, U S, t}\right], \\
& \Delta_{U S, J P, t}=+1.75-0.126 \Delta x_{U S, J P, t-1}-0.26\left[\left(x_{U S, J P}-y_{U S}\right)_{t-1}\right. \\
& \left.-0.6\left(y_{J P}-y_{U S}\right)+0.29 r p_{U S, J P, t-1}+0.67 \phi_{U S, J P, t}\right], \\
& \Delta x_{G E, J P, t}=+0.15-0.17 \Delta x_{G E, J P, t-1}-0.19\left[\left(x_{G E, J P}-y_{G E}\right)_{t-1}\right. \\
& \left.-0.6\left(y_{J P}-y_{G E}\right)_{t-1}+1.24 r p_{G E, J P, t-1}-0.67 \phi_{G E, J P, t}\right], \\
& \Delta x_{G E, J P, t}=-1.29-0.43 \Delta x_{G E, U S, t-1}-0.16\left[\left(x_{G E, U S}-y_{G E}\right)_{t-1}\right. \\
& \left.-0.6\left(y_{U S}-y_{G E}\right)_{t-1}+1.16 r p_{G E, U S, t-1}-0.67 \phi_{G E, U S, t}\right], \\
& \Delta x_{J P, U S, t}=-4.37-0.011 \Delta x_{J P, U S, t-1}-0.16\left[\left(x_{J P, U S}-y_{J P}\right)_{t-1}\right. \\
& \left.-0.6\left(y_{U S}-y_{J P}\right)_{t-1}+1.17 r p_{J P, U S, t-1}-0.67 \phi_{J P, U S, t}\right], \\
& \Delta x_{J P, G E, t}=-0.41-0.23 \Delta x_{J P, G E, t-1}-0.12\left[\left(x_{J P, G E}-y_{J P}\right)_{t-1}\right. \\
& \left.-0.6\left(y_{G E}-y_{J P}\right)_{t-1}+0.42 r p_{J P, G E, t-1}-0.67 \phi_{J P, G E, t}\right],
\end{aligned}
$$

where $x_{i j}$ represents the volume of exports (in $i$ 's currency) from country $i$ to $j, r p$ is the relative price, and $\mathrm{N}_{i j}$ is the bilateral exchange rate.

\section{Analysing Fiscal Shocks in International Models}

We analyse policy coordination in response to fiscal shocks in the context of the above model using the optimising techniques discussed at length in Caporale et al 
(2002). In brief, we wish to choose the parameters of a set of rules so as to minimise the variance of the economy when it is subject to a particular set of stochastic shocks. Moreover we do this in a game setting which might involve successive optimisations over a number of players. As the computational burden of this form of problem is considerable, we propose a simplification of the problem which will yield an identical solution for most forms of nonlinearity which are observed in large macro models. The idea here is based on the notion that any monotonic transformation of the cost function will yield an identical solution for the control variables. So if we minimise the variance of the cost function (V(.)) with respect to a set of variables $u$ then we will have exactly the same solution for $\mathrm{u}$ as if we minimised a monotonic transformation of $\mathrm{V}\left(\mathrm{e} . \mathrm{g}\right.$. $\log (\mathrm{V})$ or $\mathrm{V}^{2}$ ). We use these propositions to substantially reduce the computational problem in minimising $\mathrm{V}($.), using a special transformation based on two elements: the first is the technique of anti-thetic errors used in stochastic simulation, the second constructs a minimum set of replications which exactly reproduce the covariance matrix of the stochastic process (see Caporale et al, 2002 for further details). We explain below why our approach is more efficient than Taylors.

(a) The Taylor Method

Essentially, Taylor (1993) posits a monetary feedback rule ${ }^{2}$ for each country, using short term interest rates (RS)

$$
R S-R S^{*}=P(+4)-P+g_{1}\left(P-P^{*}\right)+g_{2}\left(Y-Y^{*}\right)
$$

where $\mathrm{P}$ is prices, and $\mathrm{Y}$ is detrended real output at time t. The $\left(^{*}\right)$ refers to target values for $\mathrm{P}$ and $\mathrm{Y}$. Equation (16) is not derived as an optimal rule, unlike the rules we derive below. Instead, it is a plausible feedback rule allowing for responses to price and output shocks (i.e. countercyclically), with alternative degrees of accommodation being possible. In the case where $g_{1}=g_{2}$, then (1) is a nominal income rule.

The issue of policy design - the setting of the $g_{i}(i=1,2)$ parameters in the present context - then is paramount. Taylor approaches this problem by using stochastic simulations. Thus for the structural macro economic model

$$
\text { Ao } Z_{t}=A(L) Z_{t}+\beta(L) u_{t}
$$

${ }^{2}$ Fiscal policy rules are not considered in the Taylor analysis. 
where $\mathrm{Z}$ are endogenous, and $\mathrm{u}$ serially uncorrelated errors, we may write the reduced form

$$
Z_{t}=\sum_{i} \theta_{i} u_{t-i}
$$

where $\theta$ is a function of $A_{0}, A(L)$ and $B(L)$, and - crucially - depends on the parameters in the policy rule $g_{1}$ and $g_{2}$. Hence we may write, in general,

$$
Y\left(g_{1}, g_{2}\right)=\sum_{i} \theta_{i} \Omega \theta_{i}
$$

as the steady state variance - covariance matrix of the Z's, where $\Omega$ is the variance-covariance matrix of the Structural Model (17).

To search for appropriate settings of the policy parameter $\mathrm{g}_{\mathrm{i}}$, Taylor evaluates the historical performance of country empirical models, varying the $\mathrm{g}_{\mathrm{i}}$ parameters in an ad-hoc way, and calibrating the consequent behaviour of the variability of the target variables prices and output. As is clear, this problem can be set up as a dynamic stochastic optimal control problem. But Taylor, for example, argues that the computation of such a general optimisation, with non linear rational expectations models coupled with stochastic shocks, is not feasible. Below, we show that with the efficiencies introduced by our method of conducting stochastic simulations such general optimisation solutions are achievable (see Caporale et al., 2002), and are employed in the analysis we present here. ${ }^{3}$

(b) The Present Method

To place ideas, Figure 1 below presents a schematic account of the main approaches, starting from the early division into complex optimal control rules on the one hand, and simple rules on the other (Point A in the figure). Later developments added stochastics to each, and simple rules were obtained optimally, and a development arising from the use of fully optimal policy rules was to place these in a game-theory form. The method developed in this project brings together optimal simple rules, in a game-theoretic setting with allowance for stochastic effects, so is represented as point $B$ in the figure. The present paper is an example

\footnotetext{
${ }^{3}$ Note that Taylor rules have also been criticised by Svensson (2003), who points out that in essence they are a commitment to simple instrument rules, and as such are an inadequate description of current monetary policy in the form of inflation targeting. He argues that monetary policy can be better understood as a commitment to targeting rules, which in fact are of the kind we consider below. Such rules are more robust and easier to verify than optimal instrument rules, and result in welfare gains.
} 
Figure 1. The Evolution of Policy Design in Models.

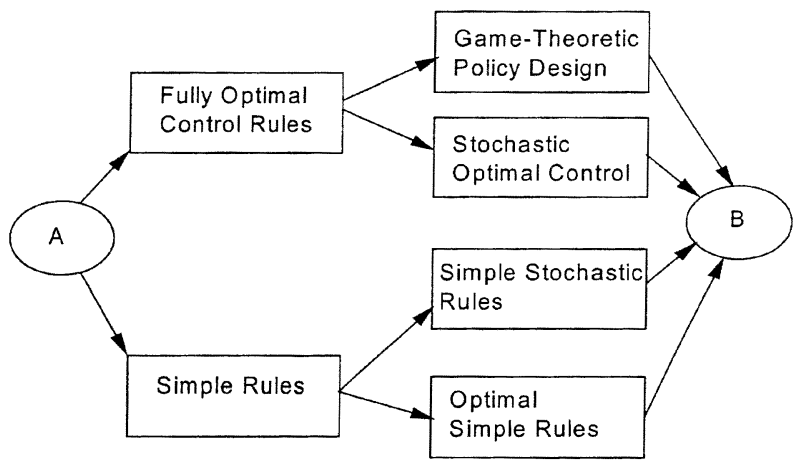

of this (see also Caporale et al (2003). Stochastic exercises are reported in Caporale et al (2003), and the various methods, including those used in this project, are described in Caporale et al (2002).

What the present study and that by Taylor share, is that the policy analysis is explicit. This separates these studies from much work in this area based on simulations of policy shocks which use arbitrary shocks to policy instruments, and do not allow for explicit policy feedbacks. In addition, the present study provides a major extension to the analysis of international policy interdependencies, by obtaining the policy rules optimally and by completing policy optimisation within a fully optimal Nash non-cooperative game, and a fully cooperative optimisation across all countries. Unlike earlier similar studies, we do not aim to calibrate likely effects on growth and inflation of an assumed exogenous fiscal consolidation, but instead describe behaviour if each country behaves optimally in controlling inflation and fiscal targets following a change in its fiscal target. Previous studies take considerable effort in approximating the fiscal shock in terms of likely changes in tax rates or expenditures, so that these are of the "appropriate" orders of magnitude. Ex-ante simulations of these effects then give conditional projections for endogenous variables for the future. These are not "forecasts" but aim to show likely orders of magnitude of the marginal effects of the assumed fiscal policy change. By contrast, we take a single fiscal exogenous "shock" to the target debt to income ratio in each country. This can be interpreted as a change in policy objectives, in an obvious way. Our policy analysis of this shock then proceeds in ascending stages: by increasing the degree of co-ordination between the G-3 countries, moving from single country optimising through to full - joint objective function -coordination. 
The present approach takes the empirical analysis in a new direction. Firstly, as explained in the previous section, it is based on an empirical model of the G3, with data coherent specifications for all its behavioural equations. In addition, macro policy is clearly articulated. Thus for monetary policy, a proportional, integral and derivative (PID) rule is used, of the form

$$
\Delta r_{t}=\mu_{p} \Delta E_{t-1}+\mu_{i} E_{t-1}+\mu_{d} \Delta^{2} E_{t}
$$

where $r$ is the real interest rate, and $E=\pi^{*}-\pi$, where $\mathrm{p}$ is inflation, is the difference of actual from desired inflation. We assume that inflation is the sole objective of the monetary authorities encompassing nominal income and exchange rate objectives. For simplicity, interest rates are taken to be the policy instrument, and we circumvent detailed issues in the conduct monetary policy by assuming the authorities directly change short- run rates. The real rate is taken, to avoid the instability which often arises when the nominal rate is used (see Nixon and Hall (1996)). ${ }^{4}$ The parameters of the rule are chosen optimally to minimise deviations in inflation from base, and weighted changes in inflation, to try and reduce the cyclical response.

In similar fashion, fiscal policy is endogenised in the policy experiments we report. It uses the rule

$$
\Delta T_{t}=\rho_{p} \Delta V_{t-1}+\rho_{i} V_{t-1}+\rho_{d} \Delta^{2} V_{t}
$$

where $T$ is the (average) income tax rate, and $V$ is the difference between the actual and target debt to GDP (GNP in the US case) ratio. Although simplified, this rule is in keeping with a number of important findings in recent research. In particular, the rule focuses upon the debt/GDP ratio, rather then the deficit/GDP ratio, and uses direct taxes as an instrument to achieve the policy objective, i.e. to stabilise deviations from target and also sharp movements in the instrument or changes in the ratio, to reduce instability. Bryant and Zhang (1996) argue that using the deficit ratio is implausible. Obviously, using a deficit to GDP target would not necessarily even achieve debt stability in the long term: this would depend on whether the (endogenously determined) growth rate and real interest rate, satisfied the required debt dynamics.

${ }^{4}$ Svensson (1998) analyses cases of "flexible" inflation targeting, i.e. when monetary authorities adopt inflation targets with some stabilisation element in policy too. 


\section{Fiscal Policy Coordination}

\section{A. Setting up the Exercises}

Fiscal optimising is done, using (2), where the $\rho_{j}(j=p, I, d)$ are derived optimally, and where, to start with, a fixed monetary rule is in place, where the weights of these latter functions have been selected using an earlier - monetary optimisation exercise (This is reported in Caporale et al (2003)). After reporting the results of this, joint optimising of fiscal and monetary weights is done, and the results compared with the fiscal-policy alone optimisation. ${ }^{5}$ The exercises we conduct comprise a simple hierarchy going from single country optimising to the fully cooperative. Specifically these exercises are as follows.

(i) Single Country Optimising

Here the optimal policy is done on a country by country basis. In each country, the national objective (i.e., minimising $V_{t}$, the difference between the actual and target debt to GDP ratio) alone drives fiscal policy. Spillovers occur between countries due to international effects on each countrys output and inflation, through familiar channels of trade flows, trade prices, and wealth effects.

(ii) Nash

Each country now again calculates optimal fiscal responses, but in the light of knowledge that each other country does likewise. In effect the optimal policy rules in the other two countries are treated as constraints in the optimisation undertaken in the first country. The final solution is then a fully optimal Nash solution, and gives a consistent set of policy rules for each country.

(iii) Fully cooperative

Finally, we let each country set fiscal policy to jointly minimise a common objective function, which takes as its arguments the unweighted deviations of the debt-income ratio in all three countries. In this exercise, it can be assumed that countries mutually agree on this joint policy, or delegate policy setting to a benevolent institution, which assigns policy stance in each country to optimise the unweighted joint objective function. $^{6}$

\footnotetext{
${ }^{5}$ Caporale et al (2001) use the same methodology to evaluate gains to cooperation in response to price shocks.

${ }^{6}$ It is well known that the problem of time-inconsistency can arise where rational agents set their expectations incorporating views of government policy, as the authorities have an incentive to manipulate rules and, by producing price inflation surprises, gain temporary output and employment effects. We check on the empirical relevance of this issue by doing an exercise based on the critical role played by the timing of expectations. Virtually no difference in solution values resulted, indicating little could be gained by reneging on prior policy commitments by the governments concerned.
} 


\section{B. The Results of the Policy Experiments}

In this sub-section, the results of policy exercises are reported, where initially the fiscal shock produces optimal fiscal responses, i.e. optimal changes in the weights of the fiscal policy rule, to minimise the deviation between actual and desired debt to income ratios. For this, the monetary rule is fixed, and the weights are optimal inflation minimising ones. These weights are those derived in a previous optimising exercise following a shock to US government expenditure (see Caporale et al. 2003). A similar procedure is followed for the Nash (ii) and fully cooperative (iii) exercises.

Each of the policy experiments reported next are initiated in the same way. We suppose that the target debt to GDP ratio is immediately reduced by 5 percent in the country in question. This is unanticipated. Then, the average tax rate is used to achieve this target, and the weights of the fiscal policy rule above are obtained optimally, i.e. they minimise the deviations between the target debt to income ratio and its actual values $\left(V_{t}\right)$ over the solution period. The idea underlying these dynamic policy games is that there is a general movement towards fiscal consolidation in the G-3, which takes the form of a reduction in planned levels of government debt as a proportion of output. The policy is implemented assuming different degrees of cooperation, starting from no cooperation, and ending with full cooperation. The purpose is to establish whether there are gains in moving from rational to cooperative policy setting, as judged by each countrys inflation and output performance. But a further ingredient is that the fiscal consolidation will have inflation output effects whichever level of cooperation exists, so this poses an additional question - would it be better if monetary policy were also selected optimally for each of these exercises? These two broad approaches to the effects of fiscal consolidation and the international policy regime, are illustrated in the two subsections which follows. In (1) fiscal policy alone is optimised. In (2), after fiscal optimising, the monetary rules are reoptimised to minimise the inflation effects of the fiscal policy changes in (a).

\section{Fiscal Optimising}

(i) Single Country Optimising

In the US, following the unannounced (and unanticipated) change in the fiscal target of 5 percent, the average tax rate is immediately raised by 40 percent and then follows a very damped oscillatory path, over the next 6-7 years. GNP falls by almost 3 percent within a year. So successful is this in moving the debt/GNP ratio 
Figure 2. US - Single Country Case.

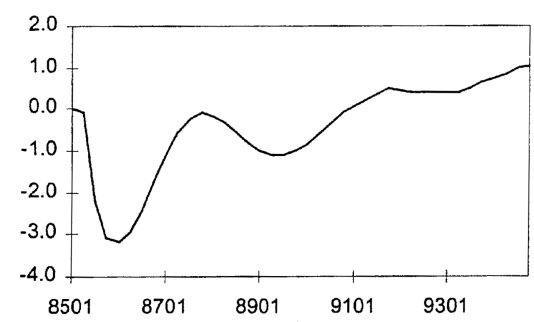

(a) GDP (\% Change from Base)

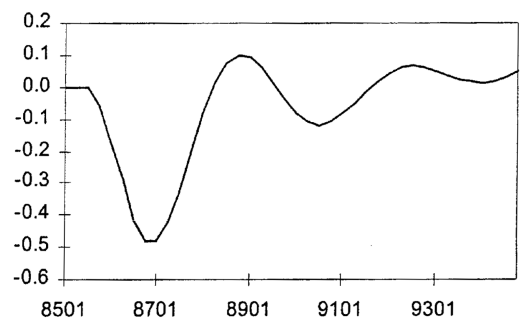

(b) Inflation (Abs. Change from Base)

to target, that fiscal policy is then revised and GNP rises above base. Thereafter GNP oscillates somewhat but generally stabilises a little above base - by approximately 1 percent (Figure 2a). Inflation follows the same oscillatory pattern, after falling by almost 0.5 percent as output falls in the first year, and converges to the vicinity of zero after about seven years. (Figure $2 b$ ).

German responses to the shock are more cyclical than is the case in the US or Japan. The initial effects of the fiscal tightening is that output first contracts, but then rises above base after 2 years since the fiscal correction actually reduces the debt/income ratio below its target by 1987 (Figure 3a). The inflation cycle closely mirrors that in output, not surprisingly. However, after the first complete cycle in activity, the movement to equilibrium is then fairly quick (Figure 3b). But, in this case, output returns to base, as does inflation.

Japan achieves the adjustment to the changed debt/income ratio most smoothly among the countries described here. Again, like Germany there is a short cycle in activity due to the tax changes: output falls, then rises in the first 2 years, by 2 percent and a little over 1 percent respectively (Figure 4a). Inflation follows suit, falling by nearly 0.4 percent first, before rising by 0.15 percent temporarily after 3 years (Figure $4 \mathrm{~b}$ ). Within 6 years adjustment to the changed objective is more or

Figure 3. Germany - Single Case

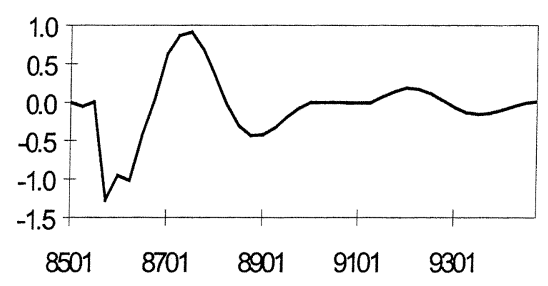

(a) GDP (\% Change from Base)

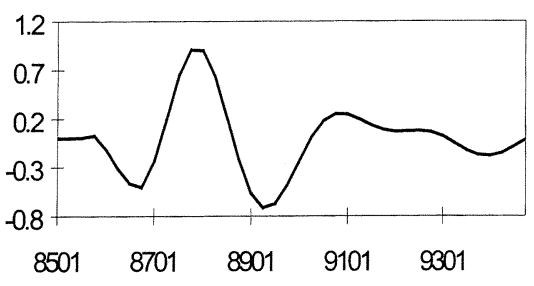

(b) Inflation (Abs. Change from Base) 
Figure 4. Japan - Singe Country Case.

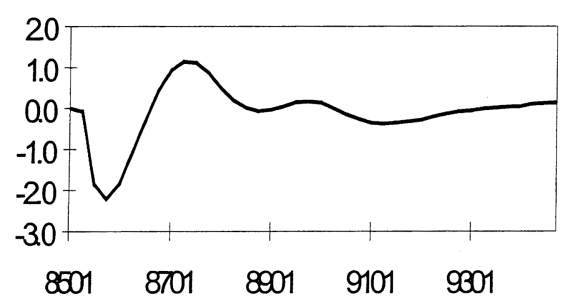

(a) GDP (\% Change from Base)

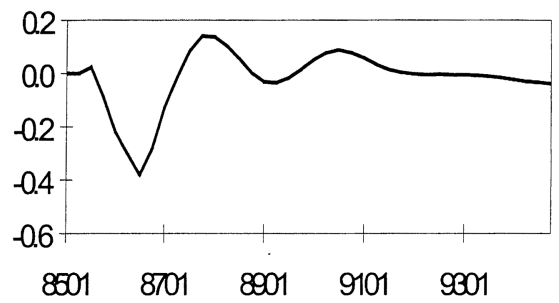

(b) Inflation (Abs. Change from Base)

less complete, with output marginally above, and inflation marginally below, the base. On the basis of these single country exercises, only in the case of the US is output above base following the fiscal consolidation, and even here, inflation remains about 0.5 higher as a result.

In the next two exercises, the same general procedure is followed: the fiscal rule is optimised following the shock to debt-income objective.

(ii) Nash Solution

In this solution, the aggregate output paths which result are substantially changed (Figure 5). Aggregate output in the US declines by 4 percent initially, then recovers, but remains below base throughout to the tune of about 2 percent. As in the single country exercise, output in Germany responds in a mainly cyclical fashion, and although these cycles are damped they persist well after 1993 when our simulations end. Only in the case of Japan does output appear to be higher after the consolidation, much as the previous literature would suggest.

The pattern of the changes in inflation in the three countries is then that inflation remains lower in the US, approaching some 1 percent below base by the end of the simulation. In Germany, the pattern is a marked cycle in inflation responding pro-

Figure 5. GDP - Nash Solution.

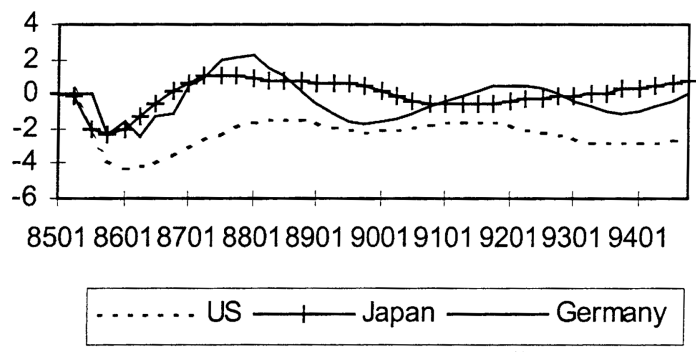


Figure 6. Inflation - Nash Solution.

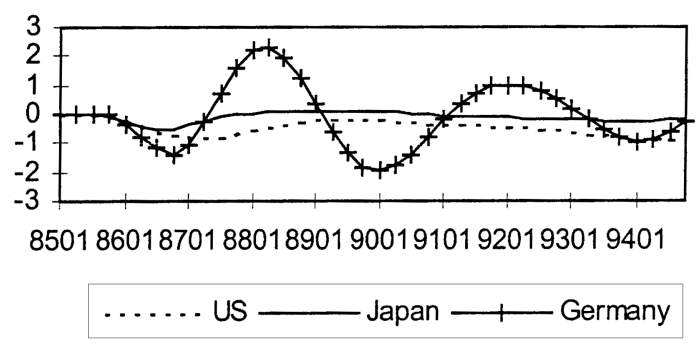

cyclically to the output changes. Japan has generally lower inflation. (Figure 6).

So to sum up, in the US a lower output - lower inflation outturn is produced when fiscal policy is adjusted optimally in a Nash game following the fiscal shock. Germany ends up by probably not changing either, but experiencing prolonged cycles of extra inflation expansions, lower inflation contractions. Japan is the only country which appears to follow the "text book" pattern of higher output with slightly lower inflation as a result of the fiscal contraction.

(iii) The Co-Operative Solution

This case can be described quickly, as it broadly resembles the previous one. (Below we return to the issue of why this may be so). Figures 7 and 8 show the comparative output and inflation changes produced by the shock when a common objective function is optimised. The outturns resemble those of the Nash solution, except that output is somewhat more adversely affected in the US. (It ends some 2.75 percent below base now, compared with 2.5 percent below base in the Nash solution). The output cycles in Germany are corresponding smaller (as is their change in inflation).

Figure 7. GDP - Cooperative Solution.

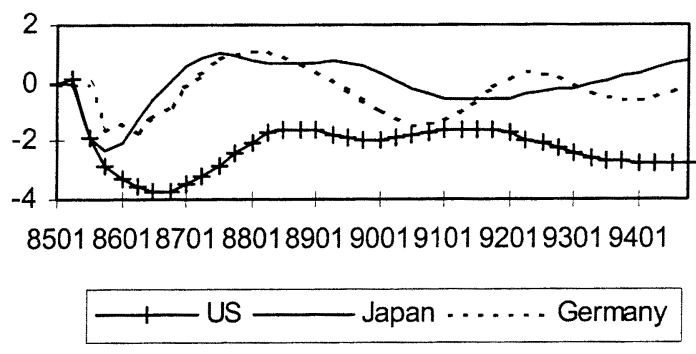


Figure 8. Inflation - Cooperative Solution.

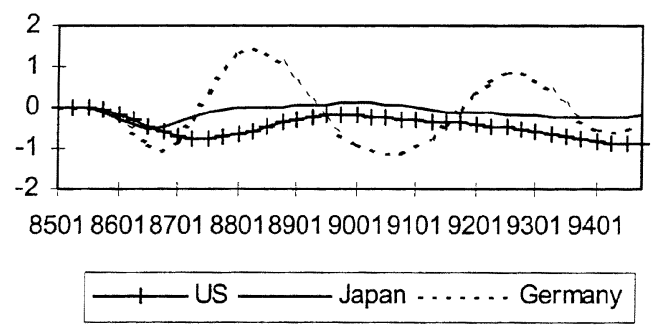

\section{Sequential Fiscal and Monetary Optimising}

As anticipated earlier, we now return to the Nash and co-operative games, and undertake further monetary optimisation by redoing each by optimising the weights in the monetary rule (1), with the optimal fiscal rules from section (1) in place.

(i) Nash

The broad pattern here is much as before. Output falls in the US over the entire solution, in Japan it is above for most of the period, including the end, while in Germany it cycles (Figure 9). Inflation, except in Germany is also much as obtained earlier. (Figure 10)

Figure 9. GDP Nash Solution with Sequential Fiscal and Monetary Optimising.
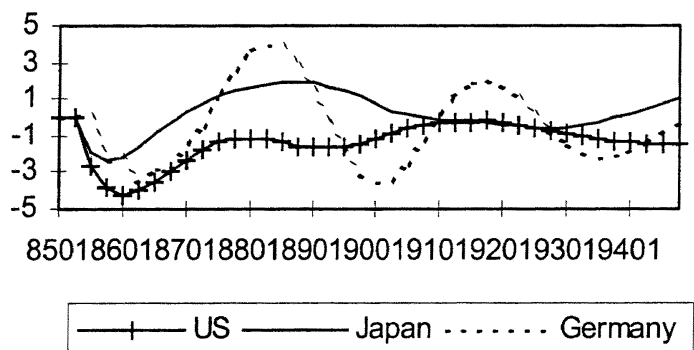

Figure 10. Inflation - Nash Solutions with Sequential Fiscal and Monetary Optimising

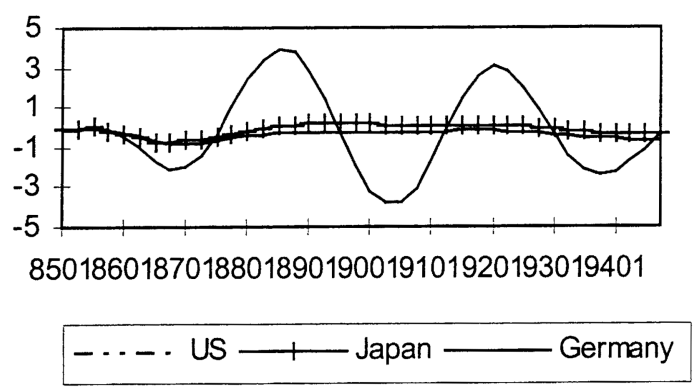


(ii) Cooperative

Moving to the cooperative game, the results now change very substantially, and this result contrasts with the move from Nash to fully cooperative behaviour in the previous exercise using only fiscal optimisation. Now output ends up higher in each country, with marked improvements in both the US and Germany taking place. In Japan output is about $1 \%$ higher throughout the solution, after the effects of the initial contraction have been overcome. (Figure 11)

The inflation outturns are also improved, there are temporary worsenings in inflation performance in Germany and Japan, but each country appears to stabilise with higher output, and inflation rates close to base as a result of cooperation. (Figure 12)

To conclude this subsection, the effects of moving from single-country or Nash non-cooperative solution to a cooperative policy for fiscal policy following a fiscal shock appear not to be substantial. These judgements concern the calculated inflation and output consequences of the different policy regimes. The conclusion is much different when monetary policy - targeted at minimising inflation - is then

Figure 11. GDP - Cooperative Solution with Sequential Fiscal and Monetary Optimising.
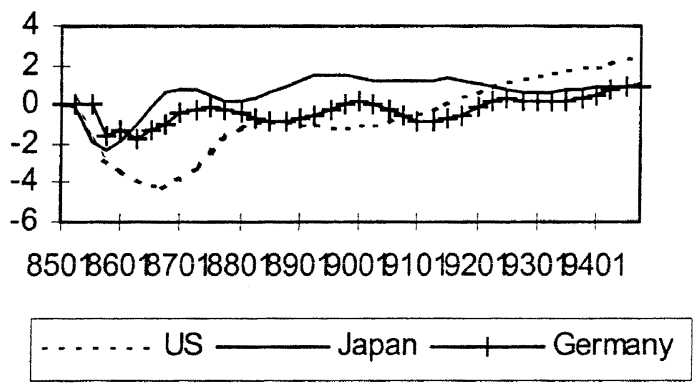

Figure 12. Inflation - Cooperative Solution with Sequential Fiscal and Monetary Optimising.

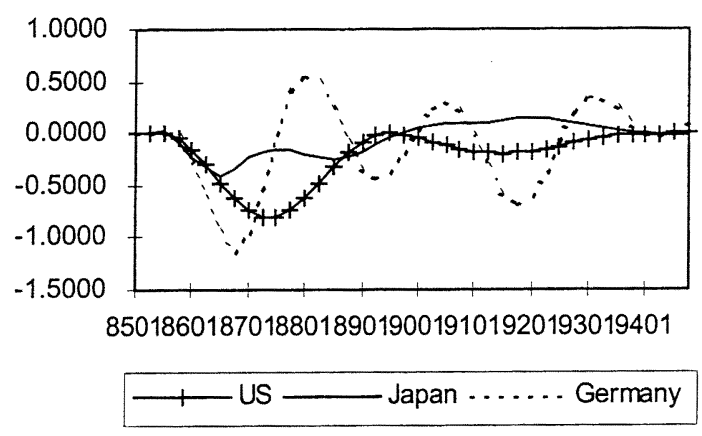


brought into play. In this case, the movement to the fully cooperative solution shows substantial gains over time for each of the countries.

\section{Conclusions}

In this paper we have outlined a new way of conducting policy experiments in international policy coordination, and illustrated it using the example of a changed target for the debt-income ratio in the G-3. This new approach to policy analysis builds on two separate approaches used in earlier work: optimal simple rules, and a game theoretic structure to the analysis of policy spillovers.

Our results suggest there are few policy externalities when the issue is simply one of using fiscal policy to achieve a changed fiscal objective. When this policy is compounded with monetary policy aimed to minimise the inflation effects of the consolidation, this conclusion is dramatically changed. Then there are very substantial externalities which can be exploited in a move to cooperation. This provides evidence that the principal transmission mechanisms lie in exchange rate and interest rate interdependencies between the G-3 countries. However, and this is the most important point concerning this study, the methods we use place the strategic interactions between (domestic) policy makers at centre stage. Consequently, it is these policy interactions which distinguish our results from other studies of international policy. Cycles of policy tightening can be induced if countries pursue national policy objectives. Only if some form of cooperation is implemented can significant improvements be made to the resulting output and inflation outturns.

\section{Acknowledgement}

We are grateful to an anonymous referee for useful comments. Financial support from ESRC grant no. L120251005, Global Institutions and Economic Policy Coordination, is also gratefully acknowledged.

Received 6 January 2003, Accepted 4 November 2003

\section{References}

Barro, R.J. (1989), "The Ricardian approach to budget deficits", Journal of Economic 
Perspectives, 3, 2, 37-54.

Bartolini, L., Razin, A. and S. Symanski (1995), "G-7 fiscal restructuring in the 1990s: macroeconomic effects", Economic Policy, 20, 109-146.

Bryant, R. (1995), "International Coordination of National Stabilisation Policies", The Brookings Institution, Washington DC.

Bryant, R.C. and L. Zhang (1996), "Intertemporal fiscal policy in macroeconomic models: introduction and major alternatives", Brookings Discussion Papers in Economics, no. 123.

Caporale, G.M. (1996), "International economic policy coordination: a brief survey of the literature”, D.P. no.22-96, Centre for Economic Forecasting, London Business School.

Caporale, G.M., Chui, M., Hall, S.G. and S.G.B. Henry (1997a), "Modelling the US economy", D.P. no.07-97, Centre for Economic Forecasting, London Business School.

Caporale, G.M., Chui, M., Hall, S.G., Henry, S.G.B and Rendu, C. (1997b), "Modelling Germany and Japan”, D.P. No. 30-97, Centre for Economic Forecasting, London Business School.

Caporale, G.M., Chui, M., Hall, S.G. and S.G.B. Henry (2001), "Coordination and price shocks: an empirical analysis", Economic Modelling, 18, 4, 569-584.

Caporale, G.M., Chui, M., Hall, S.G. and S.G.B. Henry (2002), "Modelling economic policy responses with an application to the G3", Annales d'Economie et de Statistique, 67/68, 415-433.

Caporale, G.M., Chui, M., Hall, S.G. and S.G.B. Henry (2003), "Evaluating the gains to cooperation in the G-3", Empirica, 30, 337-356.

Currie, D.A., Levine, P. and N. Vidalis (1987), "Cooperative and non-cooperative rules for monetary and fiscal policy in an empirical two-bloc model", 75-121, in R.C. Bryant and R. Portes (eds.), Global Macroeconomics: Policy Conflict and Cooperation, MacMillan, London.

Currie, D., and Levine, P. (1993), "Rules, Reputation and Macroeconomic Policy Coordination", Cambridge University Press.

Dornbusch, R. (1976), "Expectations and exchange rate dynamics", Journal of Political Economy, 84, 6, 1161-1176.

Douven, R. and Peeters, M. (1997), “GDP Spillovers in Multi-Country Models”, ESRC Macroeconomic Modelling Bureau University of Warwick, DP No 46.

Frankel, J.A. (1988), “Ambiguous multipliers in theory and in empirical models”, in R.C. Bryant et al (eds.), Empirical Macroeconomics for Interdependent Economies , 1726, Brookings.

Helliwell, J. and Padmore, T. (1985), "Empirical Studies for Macroeconomic Interdependence”, Handbook of International Economics, North Holland.

Holtham, G. and A. Hughes Hallett (1987), "International policy cooperation and model uncertainty", in R.C. Bryant and R. Portes (eds.), Global Macroeconomics: Policy Conflict and Cooperation, MacMillan, London.

Holtham, G,. Hughes-Hallett, A. and Hutson, G. (1992), "Exchange Rate Targetting as a Surrogate for International Policy Coordination", in "Blueprints for Exchange Rate 
Management" ed Miller M, Eigengreen B and Portes R, Academic Press.

Hughes Hallett, A. (1989), "What are the risks in coordinating economic policies internationally?", in R. MacDonald and M.P. Taylor (eds.), Exchange Rates and Open Economy Macroeconomics, Basil Blackwell, Oxford.

Layard, R., Nickell, S. and R. Jackman, (1991), Unemployment - Macroeconomic Performance and the Labour Market, Oxford University Press, Oxford.

McKibbin, W. (1993), "The Consequences of Fiscal Consolidation in the OECD”, Working Paper ANU.

Nixon, J. and S.G. Hall (1996), "Controlling inflation: modelling monetary policy in the 1990s”, D.P. no.04-96, Centre for Economic Forecasting, London Business School.

Oudiz, G. and Sachs, J.D. (1985), "International Policy Coordination”, in Dynamic Macroeconomic models, International Economic Policy Coordination, ed.by Buiter W and Marston R, Cambridge University Press.

Persson, T. and G. Tabellini, (1995), "Double-edged incentives: institutions and policy coordination”, CEPR Discussion Paper no. 1141.

Rogoff, K. (1985), “Can international policy coordination be counterproductive?", Journal of International Economics, 18, 199-217.

Svensson, L. (1998), “Open economy inflation targetting”, NBER Working Paper no. 6545, Cambridge, Mass., USA.

Svensson, L. (2003), "What is wrong with Taylor rules? Using judgment in monetary poliocy through targeting rules", Journal of Economic Literature, 41, 426-477.

Tanzi, Y., and Lutz, M. (1991), "Interest Rates and Government Debt: Are the Linkages Global Rather than National?", IMF Working Paper 91/6.

Taylor, J.B. (1989), "Policy analysis with a multicountry model", in R.C. Bryant, D.A. Currie, J. Frenkel, P.R. Masson, and R. Portes, eds., (1989), Macroeconomic Policies in an Interdependent World, Brookings, CEPR and IMF.

Taylor, J.B. (1993), Macroeconomic Policy in a World Economy, W.W. Norton \& Co., New York.

Taylor, J.B. (1993), "Macroeconomic Policy making in a World Economy” W.W Norton, New York.

Whitley, J. (1992), "Macroeconomic Policy Coordination in Europe" in "Aspects of Monetary Union-Model Based Simulation results" ed Barrell, R. and Whitley, J. Sage Publications, London. 